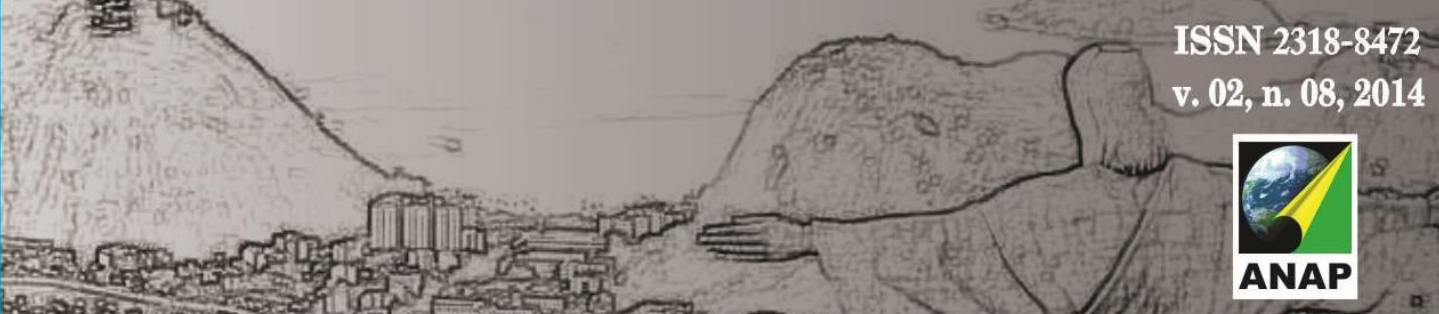

Revista Nacional de

Gerenciamento de Cidades

\title{
POLÍTICAS HABITACIONAIS, INFRAESTRUTURA E SUSTENTABILIDADE NO BAIRRO JARDINS MANGUEIRAL NA REGIÃO ADMINISTRATIVA DE SÃO SEBASTIÃO (DF)
}

\author{
Luciana Meira dos Santos Nunes ${ }^{1}$
}

\begin{abstract}
RESUMO
Este artigo trata das transformações do espaço urbano destacando as áreas residenciais, no que se refere às políticas habitacionais brasileiras, com enfoque para o empreendedorismo urbano, que privilegia os interesses do mercado imobiliário e se apropria do planejamento urbano para construir e comercializar bairros planejados, os quais já começam ser habitados possuindo infraestrutura e ações de paisagismo e sustentabilidade. Contudo tais ações perpetuam a segregação social existente no Distrito Federal, tendo em vista que a maioria dos municípios e bairros do país surge e se expandem sem um planejamento prévio. $O$ crescimento urbano gera problemas ambientais e socioeconômicos, e uma das possíveis soluções aos problemas urbanos é o planejamento. Tem aumentado nas grandes cidades brasileiras o número de condomínios destinados à habitação, ou os chamados bairros planejados, os quais são construídos com toda infraestrutura que possibilita uma melhor qualidade de vida para população residente. A pesquisa tem por base os estudos ambientais $e$ socioeconômicos que permeiam o Setor Habitacional Jardins Mangueiral, localizado na Região Administrativa de São Sebastião, no Distrito Federal. A problemática da pesquisa gira em torno das questões: a) Qual a relação entre planejamento urbano e Parceria Público-Privada? e b) Como o empreendedorismo urbano tem atuado no Distrito Federal? A metodologia desenvolvida está sendo com procedimentos de coleta de dados como a pesquisa teórica, pesquisa documental e pesquisa de campo. $O$ trabalho analisa elementos que estruturam 0 real, elementos esses que configuram o espaço urbano observado, como as habitações, os moradores, a classe social a qual os moradores dos condomínios fechados pertencem e a logística do planejamento urbano desenvolvido para as cidades como ação governamental que realiza parcerias público-privadas para criar e manter a ordem no espaço da cidade.
\end{abstract}

PALAVRAS-CHAVES: Jardins Mangueiral, políticas habitacionais, sustentabilidade.

\footnotetext{
${ }^{1}$ Professora da Secretaria de Educação do Goiás, Mestranda em Geografia, Universidade Federal de Goiás, Campus Catalão - lucianameira1@hotmail.com
} 


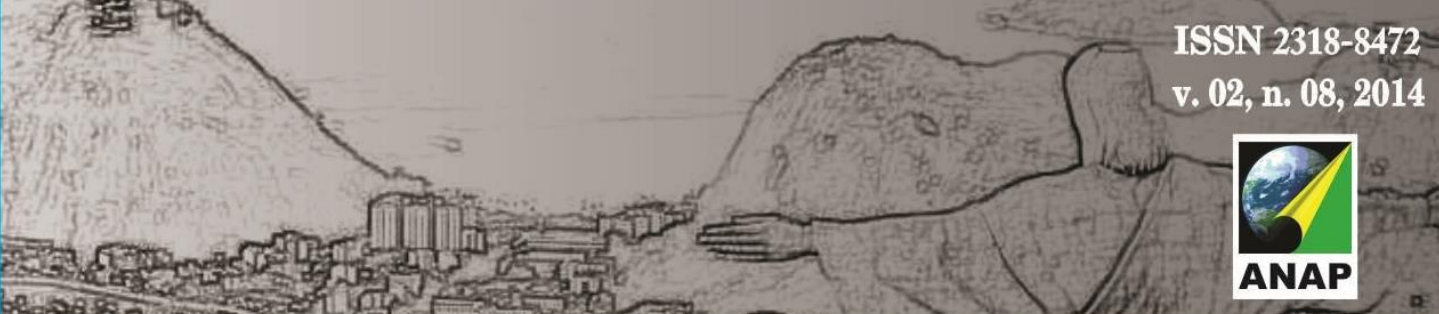

Revista Nacional de

Gerenciamento de Cidades

\title{
HOUSING POLICIES, INFRASTRUCTURE AND SUSTAINABILITY IN GARDENS IN NEIGHBORHOOD MANGUEIRAL ADMINISTRATIVE REGION SAN SEBASTIAN (DF)
}

\begin{abstract}
This article deals with the transformation of urban space highlighting the residential areas, with regard to Brazilian housing policies, with a focus on urban entrepreneurialism, which privileges the interests of the real estate market and own the urban planning to build and market planned neighborhoods, which are already beginning to be inhabited having infrastructure and landscaping actions and sustainability. However such actions perpetuate existing social segregation in the Federal District, considering that most municipalities and districts of the country arises and expand without prior planning. Urban growth leads to environmental and socioeconomic problems, and possible solutions to urban problems is planning. Has increased in large cities the number of condominiums for housing, or so-called planned neighborhoods, which are built with all the infrastructure that allows a better quality of life for residents. The research is based on the environmental and socioeconomic studies that permeate the Housing Sector Mangueiral Gardens, located in Administrative Region of San Sebastian, in the Federal District. The research of the issue revolves around the questions: a) What is the relationship between urban planning and public-private partnership? b) As urban entrepreneurialism has worked in the Federal District? The methodology is being with data collection procedures as theoretical research, desk research and field research. The paper analyzes elements that structure the real, these elements that make up the urban space observed, such as housing, residents, the social class to which the residents of gated communities belong and the logistics of urban planning developed for cities as government action conducts public-private partnerships to create and maintain order in the city space.
\end{abstract}

KEYWORDS: Mangueiral Gardens, housing policies, sustainability.

\section{POLÍTICAS DE VIVIENDA, INFRAESTRUCTURA Y SOSTENIBILIDAD EN JARDINES EN BARRIO MANGUEIRAL REGIÓN ADMINISTRATIVA SAN SEBASTIAN (DF)}

\section{RESUMEN:}

Este artículo se ocupa de la transformación del espacio urbano destacando las áreas residenciales, con respecto a las políticas de vivienda de Brasil, con un enfoque en el 


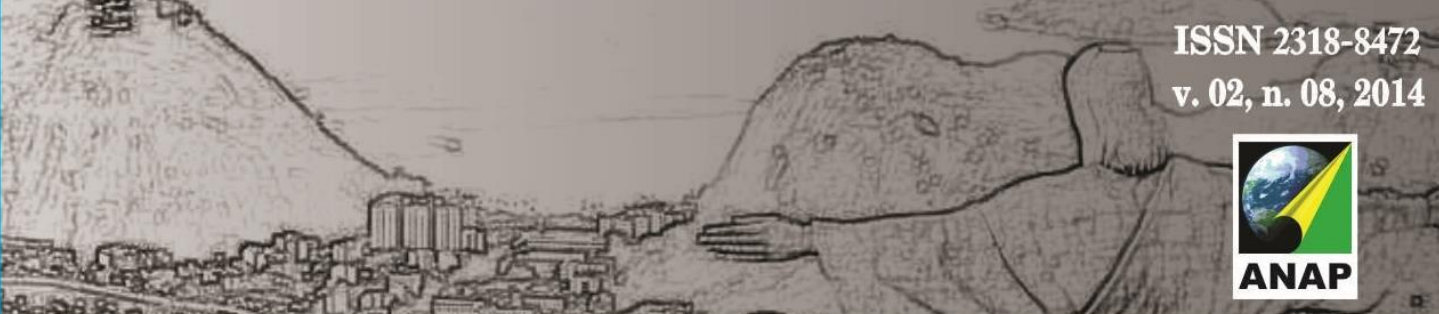

Revista Nacional de

Gerenciamento de Cidades

emprendimiento urbano, que privilegia los intereses del mercado inmobiliario y dueño de la planificación urbana para construir y barrios de mercado previsto, que ya están empezando a ser habitada tener acciones de infraestructura y paisajismo y la sostenibilidad. Sin embargo este tipo de acciones perpetúan existente segregación social en el Distrito Federal, teniendo en cuenta que la mayoría de los municipios y distritos del país surge y se expanden sin una planificación previa. El crecimiento urbano lleva a problemas ambientales y socioeconómicos, y las posibles soluciones a los problemas urbanos es la planificación. Ha aumentado en las grandes ciudades el número de condominios de vivienda, o los llamados barrios planificados, que se construyen con toda la infraestructura que permite una mejor calidad de vida de los residentes. La investigación se basa en los estudios ambientales y socioeconómicos que impregnan las viviendas del sector Mangueiral Jardines, ubicado en la Región Administrativa de San Sebastián, en el Distrito Federal. La investigación de la cuestión gira en torno a las preguntas: a) ¿Cuál es la relación entre la planificación urbana y la colaboración públicoprivada? b) Como el emprendimiento urbano ha trabajado en el Distrito Federal? La metodología es estar con los procedimientos de recolección de datos como la investigación teórica, la investigación documental y la investigación de campo. El documento analiza los elementos que estructuran el verdadero, estos elementos que componen el espacio urbano observado, como la vivienda, los residentes, la clase social a la que pertenecen los residentes de barrios cerrados y la logística de la planificación urbana para las ciudades desarrolladas como la acción de gobierno lleva a cabo las asociaciones público-privadas para crear y mantener el orden en el espacio de la ciudad.

PALABRAS CLAVE: Mangueiral Gardens, las políticas de vivienda, la sostenibilidad.

\section{INTRODUÇÃO}

Planejar o futuro das cidades envolve pensar como podem ser oferecidas condições que gerem qualidade de vida para a população urbana que está em constante crescimento. $O$ aumento da população nas áreas urbanas e a necessidade por moradias nas cidades tem criado situações que requerem por parte da sociedade como um todo e do Estado esforços no sentido de planejar o futuro das cidades.

O enfoque da pesquisa em desenvolvimento é o acesso à moradia por meio de programas habitacionais como o projeto "Minha Casa, Minha Vida" do governo federal, que tem proporcionado o financiamento da casa própria para pessoas de classe baixa e classe média. Contudo, a construção dessas residências engloba questões geográficas como ocupação e transformação do 
Revista Nacional de

Gerenciamento de Cidades

espaço, processo de urbanização, segregação social e residencial, planejamento urbano, políticas públicas, sustentabilidade, expansão das cidades e tantos outros fatores que posteriormente serão analisados.

O objeto de estudo é o novo bairro Jardins Mangueiral, localizado na Região Administrativa de São Sebastião, no Distrito Federal. O novo bairro está em construção desde 2009 e tem previsão para ficar totalmente pronto em 2015. Ele faz parte da primeira parceria-público-privada do país, no setor habitacional, formada entre o Governo do Distrito Federal (GDF), a Caixa Econômica Federal e por 6 empresas privadas: 1- Bairro Novo - Odebrecht (Realizações Imobiliárias); 2- Construtora Villela e Carvalho; 3- Silco Engenharia; 4- Sol Tec Engenharia; 5- Emplavi e 6- Geo lógica - Consultora Ambiental. A seleção dos compradores é realizada em parceria com órgãos públicos do CDF: a Companhia de Desenvolvimento Habitacional do Distrito Federal (CODHAB) e a Secretaria de Habitação, Regularização e Desenvolvimento Urbano (SEDHAB).

O empreendimento constitui um bairro planejado, onde serão construídas no total de 8.000 unidades habitacionais, divididas em 15 quadras administradas como condomínio fechado. Cada quadra possui aproximadamente 640 habitações que são compostas por prédios de 4 andares, sendo 16 apartamentos em cada prédio, e casas de dois e de três quartos, formando 3 estilos diferentes de moradia, com preços também diferentes. Cada quadra tem área de lazer, quadra de esportes, e sistema de segurança.

Até o momento foram entregues 11 quadras, e as outras estão em processo de construção. Com o número de habitações, a previsão é que só no bairro tenham aproximadamente 25.000 habitantes em 2016. Sendo que atualmente a população estimada da Região Administrativa de São Sebastião é de 100.000 habitantes. Isso revela a expansão metropolitana de Brasília e do Distrito Federal como um todo. 
Revista Nacional de

Gerenciamento de Cidades

Assim, o objetivo central da pesquisa será analisar a relação do planejamento urbano na efetivação de políticas habitacionais no bairro Jardins Mangueiral, em São Sebastião (DF). E também analisar os fatores relacionados à infraestrutura e sustentabilidade que estão sendo utilizados nas construções dos bairros planejados.

\section{EXPANSÃO URBANA NO DISTRITO FEDERAL}

A população do Distrito Federal tem aumentado aceleradamente nos últimos anos, e esse fato tem gerado dificuldades no setor habitacional. Os principais problemas referem-se à forma de ocupação do território e ao valor dos imóveis. Os valores dos imóveis funcionam como barreiras para aquisição da casa própria, principalmente nas áreas próximas ao centro da cidade, 0 Plano Piloto.

Com base nessa realidade o governo Federal tem efetuado políticas públicas, como o projeto "Minha casa, minha vida", que facilitam e possibilitam a compra da casa própria em lugares estrategicamente planejados. Assim, estão sendo realizadas Parcerias - Público - Privadas para construírem e transformarem o espaço, criando os bairros planejados, como o condomínio Jardins Mangueiral, o qual será analisado na pesquisa.

O novo bairro Jardins Mangueiral representa a expansão da cidade de São Sebastião, a qual é umas das Regiões Administrativas do Distrito Federal. Castells (1983, p.35) afirma que o processo de formação das cidades está na base das redes urbanas e condiciona a organização social do espaço. Logo, no DF, as cidades que se localizam ao redor do Plano Piloto formam junto com o centro um tecido urbano.

Numa ordem teórica, fica claro que a cidade é o lugar geográfico onde se instala a superestrutura político-administrativa de uma sociedade que chegou a um ponto de desenvolvimento técnico e social (natural e cultural) de tal ordem que existe uma diferenciação do produto em reprodução simples e ampliada da força de trabalho, 


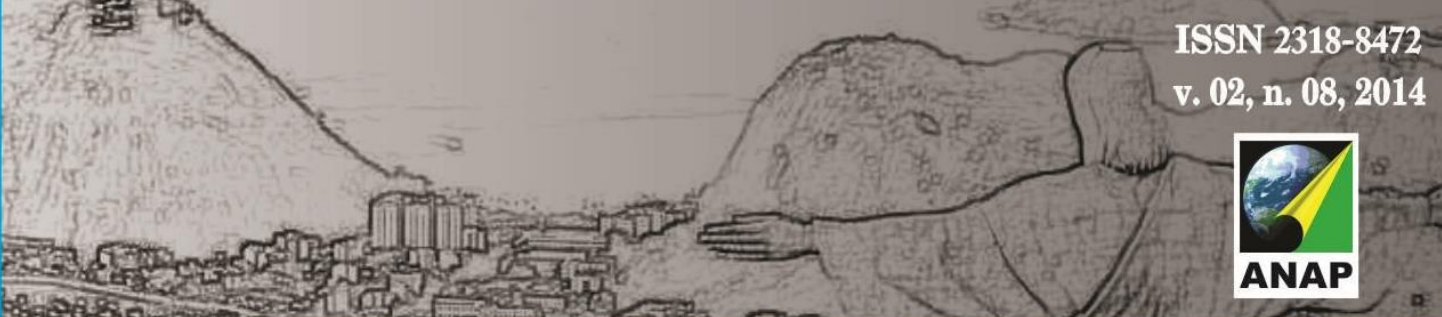

Revista Nacional de

Gerenciamento de Cidades

chegando a um sistema de distribuição de troca, que supõe a existência: de um sistema de classes sociais; de um sistema político permitindo ao mesmo tempo o funcionamento do conjunto social e o domínio de uma classe; de um sistema institucional de investimento, em particular no que concerne à cultura e à técnica e de um sistema de troca com o exterior. Esta análise, mesmo rápida, mostra 0 "fenômeno urbano" articulado à estrutura de uma sociedade. (CASTELLS, 1983, p. 42)

No estudo acadêmico sobre Geografia Urbana e Planejamento Urbano há diversos autores que explicam os fatores positivos e negativos do processo de urbanização, e umas das análises que se destacam tem sido 0 empreendedorismo urbano no setor habitacional, como forma de associar os interesses da população, do Estado e das empresas privadas do ramo da construção civil. A proposta da pesquisa será associar as teorias sobre planejamento e empreendedorismo urbano com o que tem acontecido na prática, no Distrito Federal. Castells (1983, p.46) explica que o termo urbanização refere-se ao mesmo tempo à constituição de formas espaciais específicas das sociedades humanas, caracterizadas pela concentração significativa das atividades e das populações num espaço restrito.

\begin{abstract}
Em vez de falar de urbanização trataremos do tema da produção social das formas espaciais. No interior dessa problemática, a noção ideológica de urbanização refere-se ao processo pelo qual uma proporção significativamente importante da população de uma sociedade concentra-se sobre um certo espaço, onde se constituem aglomerados funcional e socialmente interdependentes do ponto de vista interno, e numa relação de articulação hierarquizada (rede urbana). (CASTELLS, 1983, p. 47)
\end{abstract}

Sobre a área de pesquisa, Jardins Mangueiral, por ser um bairro residencial, seus moradores dependem dos serviços oferecidos no centro de São Sebastião, como supermercados, postos de saúde, postos de gasolina, drogarias, e o comércio em geral e também dos serviços administrativos e comerciais disponíveis somente no Plano Piloto. Assim, há uma hierarquia entre as cidades do DF, aonde umas apresentam predominância de setores residenciais, outras de setores hospitalares, outras de setores universitários e 
Revista Nacional de

Gerenciamento de Cidades

um espaço simultaneamente fragmentado e articulado. Fragmentado por separar na mesma cidade os setores comerciais, setor hospitalar, setor universitário, setor habitacional, ou seja, diversos setores que disponibilizam diferentes tipos de serviços. Esse espaço também é articulado porque o fluxo de transporte, pessoas, mercadoria e comunicação interligam todos esses setores. Como a pesquisa irá trabalhar com a proposta do bairro planejado Jardins Mangueiral, o fluxo que se destaca são as pessoas que residem em um setor e trabalham nos setores que prestam serviço. Especificadamente, moram no Jardins Mangueiral, que se localiza na Região Administrativa de São Sebastião e trabalham, em sua maioria, no Plano Piloto.

Sobre o espaço urbano ser fragmentado e articulado, Corrêa (1989) explica que esta divisão articulada é a expressão espacial de processos sociais, introduz-se um momento de apreensão do espaço urbano, o que se mostra como um reflexo da sociedade. Assim, o espaço da cidade capitalista é fortemente dividido em áreas residenciais segregadas, refletindo a complexa estrutura social em classes. Isso se mostra bem presente nas cidades brasileiras e especificamente na cidade analisada, tendo em vista que Brasília foi construída e planejada para ser sede do governo, sendo habitada por consequência por funcionários públicos. Contudo com o desenvolvimento, a oportunidade de emprego e a expansão ocasionada pelo mercado de trabalho em todos os setores propiciaram o crescimento de bairros que agregaram pessoas de baixa renda. A segregação se deu no setor habitacional, pois 0 centro foi planejado para ser local de trabalho e moradia dos funcionários do Distrito Federal e os bairros periféricos cresceram abrigando trabalhadores dos mais diversos setores. Corrêa (1989) afirma que:

As áreas residenciais segregadas representam papel ponderável no processo de reprodução das relações de produção, no bojo do qual se reproduzem as diversas classes sociais e suas frações: os bairros são os locais de reprodução dos diversos grupos sociais. Fragmentada, articulada, reflexo e condicionante social, a cidade é também o lugar onde as diversas classes sociais vivem e se reproduzem. Isto envolve o quotidiano e o futuro próximo, bem como 


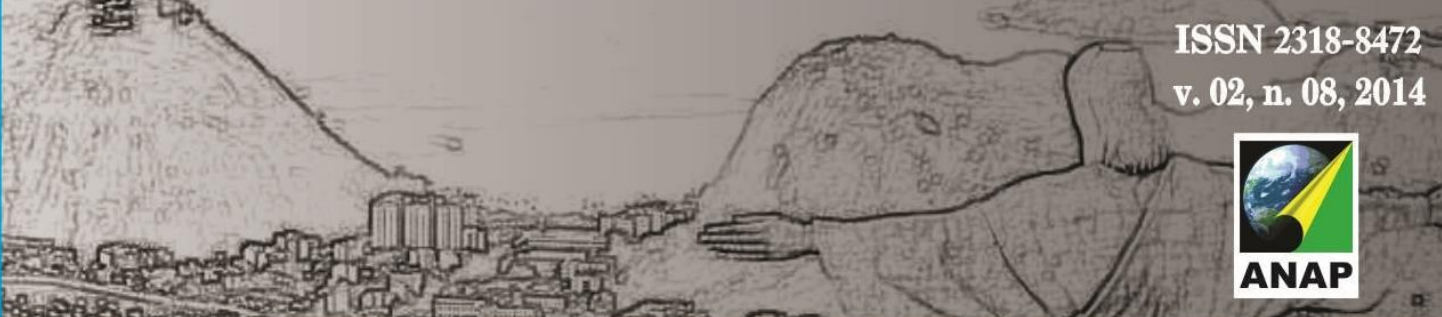

Revista Nacional de

Gerenciamento de Cidades

as crenças, os valores e mitos criados no bojo da sociedade de classes e, em parte, projetados nas formas espaciais: monumentos, lugares sagrados, uma rua especial. O espaço urbano assume assim uma dimensão simbólica que, entretanto, é variável segundo os diferentes grupos sociais, etários. Mas o quotidiano e o futuro próximo acham-se enquadrados num contexto de fragmentação desigual do espaço, levando aos conflitos sociais, como as greves operárias, as barricatas e os movimentos sociais urbanos. O espaço da cidade é assim, e também, o cenário e o objeto das lutas sociais, pois estas visam, afinal de contas, o direito à cidade, à cidadania plena e igual para todos. (CORRÊA, 1989, p.9).

\section{ESPAÇO E SEGREGAÇÃO SOCIAL}

A produção do espaço também está associada à segregação social, quando as características dos setores habitacionais são diferenciadas pela classe social dos compradores e moradores das residências. No caso específico do Jardins Mangueiral, o programa habitacional nesta área foi destinado a famílias com renda entre 4 a 12 salários mínimos. Ou seja, os programas do governo também segregam as pessoas pela classe social, tendo em vista que quem recebe um salário inferior, só pode adquirir uma residência em um local que não seja privilegiado com completa infraestrutura urbana e que não seja próximo ao centro da cidade, no caso Brasília. Assim, as classes menos favorecidas economicamente sempre residem em locais distantes do centro e as classes médias estão tendo a oportunidade de habitar mais próximo da capital.

O endurecimento da cidade é paralelo à ampliação da intencionalidade na produção dos lugares, atribuindo-lhes valores específicos e mais precisos, diante dos usos preestabelecidos. Esses lugares, que transmitem valor às atividades que aí se localizam, dão margem a uma nova modalidade de criação e escassez, e a uma nova segregação. Esse é o resultado final do exercício combinado da ciência e da técnica e do capital e do poder, na reprodução da cidade. (SANTOS, 2002, p. 251)

Existe a segregação social e residencial entre os habitantes de Brasília, de São Sebastião e agora do novo bairro Jardins Mangueiral, essa segregação se nota pelos modelos das construções das habitações, pelos automóveis, pelo 
Revista Nacional de

Gerenciamento de Cidades

fato de ser um bairro com quadras em sistema de condomínio fechado. E mesmo dentro do próprio bairro, se observa a segregação durante as reuniões entre os condôminos, entre os moradores dos apartamentos e das casas, tendo em vista que os apartamentos tem um valor inferior aos das casas, que por sua vez também se diferenciam por serem divididas entre casas de dois quartos ou casas de três quartos. Tudo isso revela aparentemente indiretamente uma segregação social e residencial. E todas essas variáveis mostram o processo de formação, transformação e perpetuação de divisão das cidades.

\section{O EMPREENDEDORISMO URBANO}

O empreendedorismo urbano está crescendo também devido às condições de financiamento realizadas pelas parcerias entre o Estado e os bancos, que facilitam o acesso ao crédito, para trabalhadores que comprovem ter condições de pagar. Sobre os processos que envolvem a compra da casa própria e a relação entre comprador, Estado e empresas privadas, Rodrigues (1997), esclarece que o preço da casa (terra / edificação) é extremamente elevado, pois no cômputo entra a renda (do proprietário da terra), o lucro (das indústrias de insumo e construção), e os juros (dos financistas). No caso da área de estudo, o condomínio Jardins Mangueiral, o proprietário da terra é o Estado, as indústrias são as construtoras privadas e o banco financiador é a Caixa Econômica Federal.

Assim, devido ao envolvimento do Estado, das construtoras e dos bancos que financiam os imóveis aos compradores, o preço final da casa/apartamento é sempre elevado, e essa lógica tem se expandido para classe média, que está em ascensão social, na forma do empreendedorismo urbano, que vê na venda de imóveis em bairros planejados um excelente negócio lucrativo, tendo em vista o crescente número de consumidores que almejam ter: casa própria, conforto e segurança. 
Revista Nacional de

Gerenciamento de Cidades

No Brasil, atualmente, aos motivos semelhantes de crescimento econômico, associado à formação de famílias com poucos filhos e o crescente número de pessoas nos centros urbanos, tem feito surgir nos subúrbios diferentes tipos de bairros planejados, ocasionado pela demanda de habitações. Essas habitações seguem um estilo único por serem casas pequenas, contudo o bairro já nasce com toda infraestrutura urbana necessária para uma melhor qualidade de vida, como é o exemplo do condomínio Jardins Mangueiral.

A escolha do lugar é fundamental para as grandes empresas. Isso engloba a logística do lugar na possibilidade da reprodução do capital. O capital sempre trabalha com a questão locacional, temos assim o uso do território para investimento na produção. Logo, a escolha do lugar onde está em construção o novo bairro planejado Jardins Mangueiral não foi feita ao acaso. Houveram por parte das empresas construtoras estudos sobre a localização da área, tanto nos aspectos geográficos físicos como sociais.

A produção do espaço urbano tem os seus agentes, quando vemos as Parcerias - Público - Privadas. O bairro Jardins Mangueiral representa esta ação conjunta do Estado e empresas privadas para construir e transformar o espaço, em uma ação conjunta que David Harvey (2005) coloca como Empreendedorismo urbano, nas chamadas Parcerias-Público-Privadas.

Segundo Costa (2009), o planejamento urbano de uma cidade é geralmente feito por acordos entre agências governamentais e empresas privadas. Esse acordo pode ser exemplificado com a construção do bairro Jardins Mangueiral, onde o governo do Distrito Federal em acordo com empresas construtoras se uniram para formalizar e construir um bairro planejado, com estrutura adequada para o desenvolvimento urbano.

No caso específico do Jardins Mangueiral, a proposta de condomínio fechado retira do governo a responsabilidade de manter os serviços básicos de segurança, limpeza e infraestrutura, tendo em vista que as taxas de condomínio, administrada por empresas privadas, é que serão responsáveis 
Revista Nacional de

Gerenciamento de Cidades

por esses serviços. Além disso, o empreendedorismo se configura porque as construtoras organizaram, em parceria com o governo, a construção de um bairro planejado em um lugar estratégico, visando o crescimento urbano futuro do local, que será dado pelas ofertas de diversos centros comerciais, destinadas aos moradores que estão em processo de ascensão social.

O complexo trabalho de planejar o urbano envolvem questões históricas, principalmente referentes ao capital, tendo em vista que na atualidade, quem pode ter qualidade de vida tem que poder financiar, logo, o planejamento urbano, na maioria das vezes, é destinado a uma determinada parcela da população.

Segundo Harvey (2005), o novo empreendedorismo tem, como elemento principal, a noção de "parceria público-privada", em que a iniciativa tradicional local se integra com o uso dos poderes governamentais locais, buscando e atraindo fontes externas de financiamento, e novos investimentos diretos ou novas fontes de emprego. A atividade da parceria público-privada é empreendedora, pois, na execução e no projeto, é especulativa, e, portanto, sujeita a todos os obstáculos e riscos associados ao desenvolvimento especulativo. E o empreendedorismo enfoca muito mais a economia política do lugar do que do território.

No setor habitacional se desenvolve o empreendedorismo urbano, relacionado à obtenção de lucro por meio da construção de novos bairros planejados. Agrega-se valor às casas e habitações que serão construídas em meio a áreas verdes, com infraestrutura completa, que inclui água, esgoto, iluminação pública, segurança, áreas de lazer, vias pavimentadas, enfim, tudo que gera maior conforto e segurança aos moradores.

O bairro em estudo foi planejado e adota práticas relacionadas à sustentabilidade, essas ações planejadas contemplam as amplas áreas verdes existentes nas quadras e em todo bairro, a cidade compactada é representada pelo tamanho pequeno das residências, assim um número maior de pessoas ocupam um espaço menor e também há no bairro um centro de práticas 


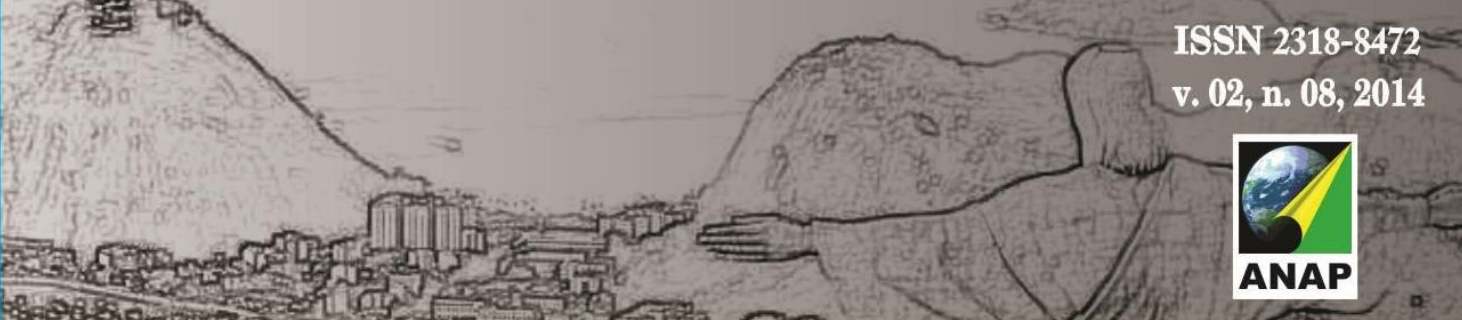

Revista Nacional de

Gerenciamento de Cidades

sustentáveis que promove ações voltadas para o meio ambiente, como cursos gratuitos aos moradores para aprenderem sobre coleta seletiva, reciclagem de produtos, reaproveitamento do material orgânico para adubagem dos diversos jardins do bairro, culinária sustentável, entre outros.

Figura 1 - Modelo das casas: 6 residências estilo sobrado no Jardins Mangueiral - (DF)

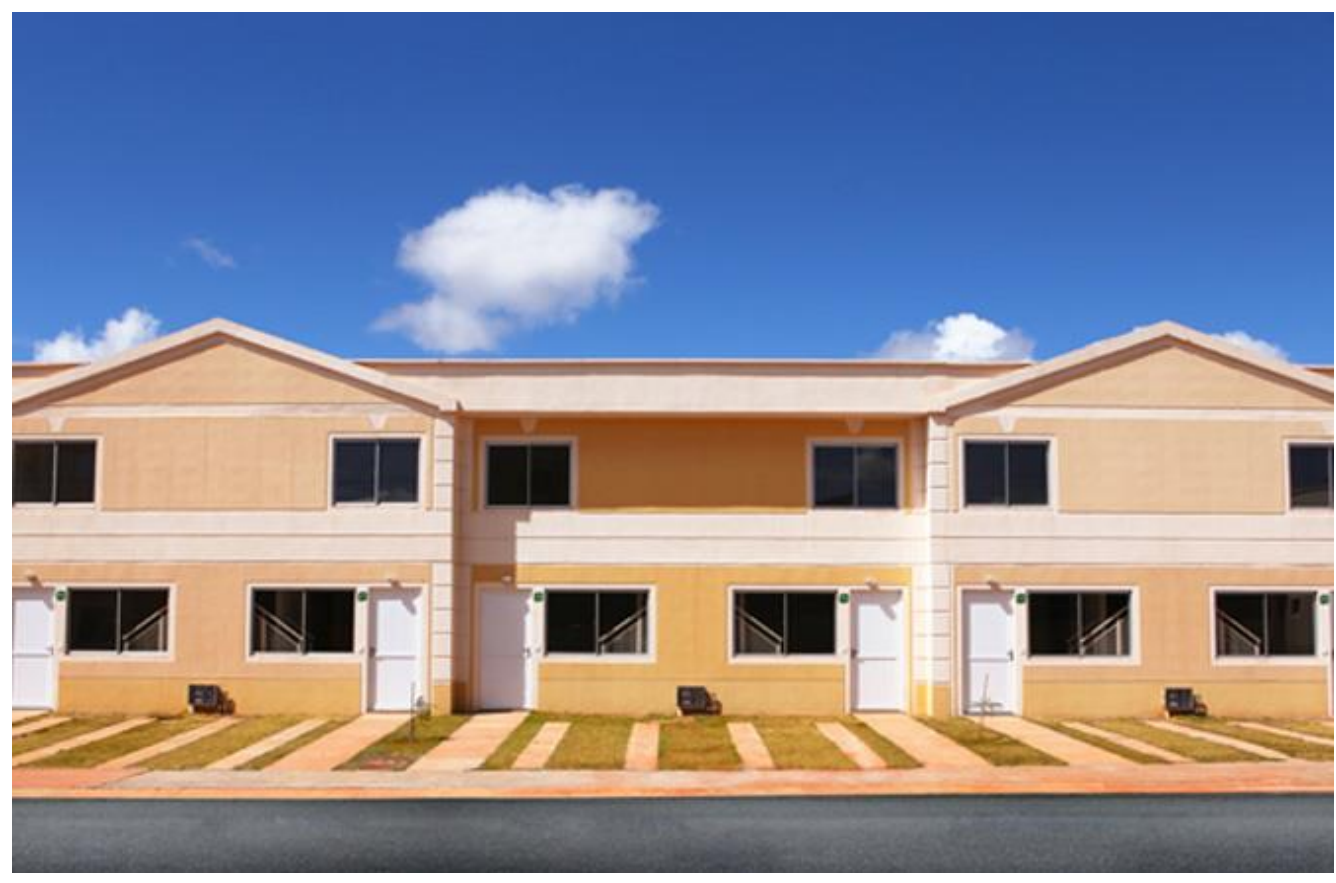

Fonte: pesquisadora (2013)

Os bairros planejados, em formato de condomínios fechados, que estão em processo de construção no Brasil, podem ser associados com as grandes corporações imobiliárias, com o capital fundiário, com a especulação imobiliária enfim, que valoriza os melhores lugares das cidades em detrimentos de outros, valorização essa que se dá pela proximidade do bairro com o centro da cidade, no caso do Jardins Mangueiral, a proximidade com o Plano Piloto, e isso engloba o circuito espacial da produção, nesse caso, na produção de residências em bairros planejados.

\section{INFRAESTRUTURA E SUSTENTABILIDADE}


Revista Nacional de

A sustentabilidade tem tido destaque no projeto de implantação do Jardins Mangueiral. O projeto original do empreendimento informa que o bairro é marcado por ações de sustentabilidade em todas as fases de construção e mesmo após a entrega das chaves. Isso significa uma atuação econômica, ambiental, social e culturalmente responsável no entorno do projeto, bem como nos condomínios e ruas do bairro.

As ações que se destacam nas obras são, segundo o empreendimento, o modelo construtivo ambientalmente correto, com redução de resíduos e de utilização de madeiras, e a contratação de mão-de-obra local, isto é, trabalhadores que habitam na cidade de São Sebastião, gerando assim, emprego e renda na região.

Outro fator ligado à sustentabilidade refere-se às ações que estão sendo implantadas no bairro em parceria com as empresas construtoras, como a Bairro Novo - Odebrecht e a Associação dos Moradores, onde em ação conjunta há o incentivo de hábitos e práticas sustentáveis, como o plantio de mudas típicas do cerrado ao longo da avenida principal; oferta de cursos gratuitos aos moradores, informações por meio de panfletos e e-mails, palestras, reuniões comunitárias com sobre: o uso consciente dos recursos naturais, a redução no consumo de água e energia, a redução nas despesas do condomínio o reaproveitamento de materiais recicláveis e a instalação nas ruas e nas quadras de equipamentos que facilitam a coleta seletiva e a reciclagem do lixo.

O bairro possui também um espaço reservado para práticas interligadas a educação ambiental. O espaço é do Instituto Ecóanama, e a missão desse instituto no bairro é gerar condições para o desenvolvimento sustentável, onde são ofertados cursos profissionalizantes, de educação ambiental, de reaproveitamento de resíduos, de produção de alimentos, além de espaço para cultivo de plantas nativas e espaço para manifestações artísticas e culturais, 


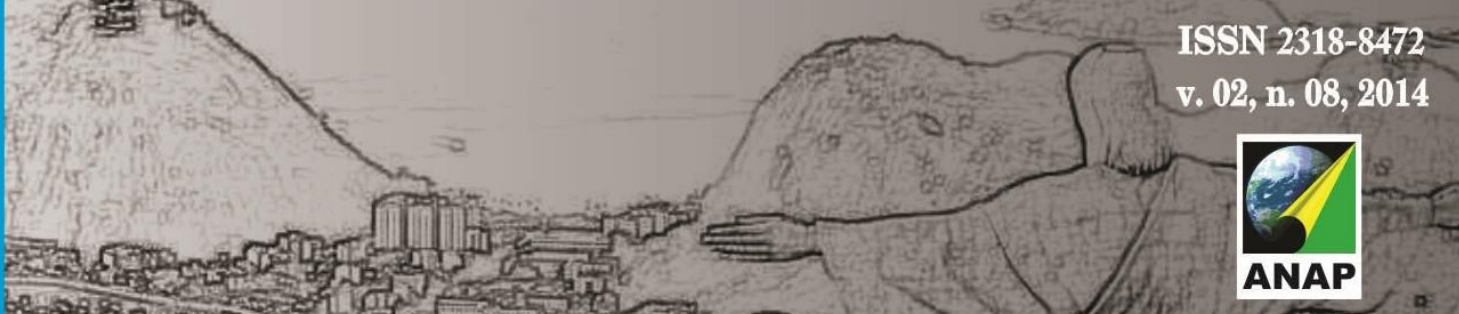

Revista Nacional de

Gerenciamento de Cidades

esse espaço pode ser utilizado pelos moradores do bairro e pelos moradores da cidade de São Sebastião e entorno.

Figura 4 - Imagem a área de lazer de uma das quadras do bairro Jardins Mangueiral

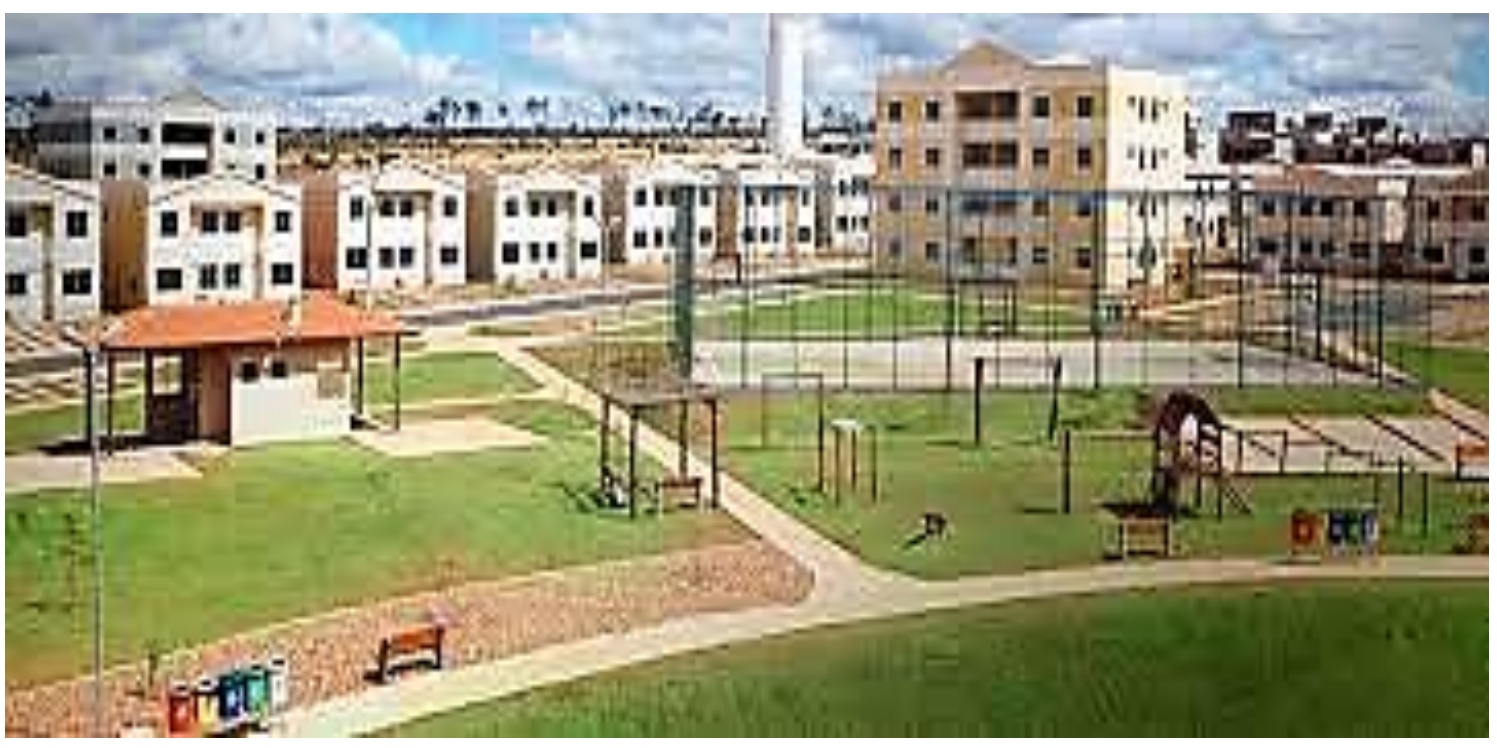

Fonte: https://www.google.com.br/. Acesso em 20/05/2014

Outro fator ligado ao paisagismo e à questão ambiental é o fato das 15 quadras que compõe o bairro terem recebido nomes de frutos e flores do cerrado. Uma forma de homenagear a vegetação típica da região e incentivar a plantação dessas plantas em todas as áreas verdes do bairro. Os nomes das quadras, a quantidade de habitações e o período de entrega das unidades estão dispostos no quadro a seguir:

Quadro 1 - Nomes das quadras e número de habitações

\begin{tabular}{|c|l|c|c|}
\hline QC* $^{*}$ & $\begin{array}{c}\text { Denominação do } \\
\text { Condomínio ** }\end{array}$ & $\begin{array}{c}\text { № Unidades } \\
\text { Habitacionais }^{* *}\end{array}$ & $\begin{array}{c}\text { Início Entrega de } \\
\text { Chaves }\end{array}$ \\
\hline 01 & Jacarandás & 442 & jan/2013 \\
\hline 02 & Muricis & 422 & mai/2013 \\
\hline 03 & Pequis & 530 & mar/2013 \\
\hline
\end{tabular}




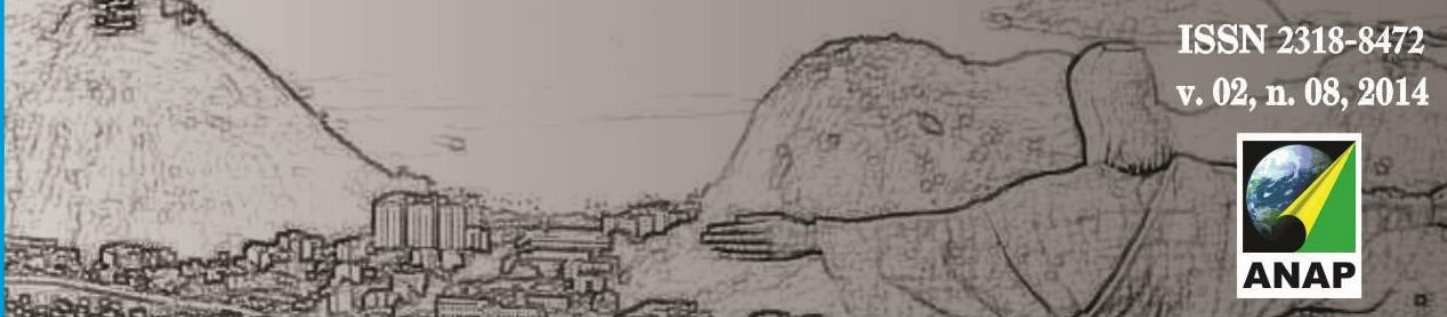

Revista Nacional de

Gerenciamento de Cidades

\begin{tabular}{|c|l|c|c|}
\hline QC$^{*}$ & \multicolumn{1}{|c|}{$\begin{array}{c}\text { Denominação do } \\
\text { Condomínio }\end{array}$} & $\begin{array}{c}\text { № Unidades } \\
\text { Habitacionais }\end{array}$ & $\begin{array}{c}\text { Início Entrega de } \\
\text { Chaves }\end{array}$ \\
\hline 04 & Tinguis & 480 & out/2013 \\
\hline 05 & Palmeiras & 440 & out/2013 \\
\hline 06 & Salácias & 564 & jun/2014 \\
\hline 07 & Tapiriris & 460 & abr/2014 \\
\hline 08 & Quaresmeiras & 574 & set/2014 \\
\hline 09 & Jatobás & 476 & dez/2014 \\
\hline 10 & Caviúnas & 668 & out/2012 \\
\hline 11 & Angelins & 634 & set/2012 \\
\hline 12 & Mangabeiras & 420 & abr/2011 \\
\hline 13 & Buritis & 624 & mai/2012 \\
\hline 14 & Acácias & 616 & ago/2011 \\
\hline 15 & Ipês & 650 & jan/2012 \\
\hline & Total de Unidades & 8.000 & \\
\hline
\end{tabular}

${ }^{*} \mathrm{QC}=$ Quadra Condominial;

** Os condomínios no Setor Habitacional Jardins Mangueiral possuem nomes de árvores do cerrado em homenagem ao bairro que busca mecanismos para a sustentabilidade como, por exemplo, a coleta seletiva, o respeito às áreas verdes e o cumprimento do plano de urbanismo.

${ }^{* * *} \mathrm{O}$ quantitativo de unidades habitacionais refere-se ao total de casas e apartamentos em cada Condomínio.

Fonte: http://www.bairrojardinsmangueiral.org.br/condominos-do-bairro-jm. Acesso em 20/05/14.

No bairro outro elemento importante no paisagismo e nas ações sustentáveis está a grande quantidade de gramados, que proporciona além da beleza um clima menos quente, evitando a impermeabilização em todas as áreas, como ocorre na maioria das cidades.

De acordo com informações da empresa Grameira Jiquitaia, o uso de gramados trazem diversos benefícios para cidade como um todo, dentre os 
Revista Nacional de

Gerenciamento de Cidades

benefícios destacamos e explicamos alguns: a valorização do imóvel; a redução da poluição, pois as gramas filtram o ar, auxiliam na decomposição dos poluentes; diminuem a poluição sonora. Além desses fatores o gramado atua na produção de oxigênio, quando a grama absorve o dióxido de carbono da atmosfera, realiza o metabolismo dele e libera oxigênio paro o meio ambiente. Outros benefícios são a reposição e filtração da água subterrânea, pois a água de escorrimento superficial em áreas urbanas pode transportar muitos poluentes, e a grama atua como filtro natural, reduzindo a poluição e purificando a água que passa através da zona das raízes.

O gramado também atua no controle da erosão e enxurradas, devido sua estrutura de sistemas radiculares, absorvem água da chuva. Assim, quanto maiores as áreas gramadas nas cidades, maior a permeabilidade do solo ás águas da chuva, diminuindo o escorrimento superficial e consequentemente 0 efeito das enxurradas. Além de todos esses benefícios, a superfície macia e maleável dos gramados representa um lugar seguro e econômico para a prática de esportes e de recreação, favorecendo a saúde física e mental dos habitantes.

Por tanto, o Jardins Mangueiral usufrui de todos esses benefícios, pois em todas as ruas e quadras do bairro existem áreas gramadas, como é representado nas fotografias abaixo. Seria interessante para as cidades, substituir as áreas de cimento e asfalto por grama, pois além da beleza traz esses benefícios para população e para o meio ambiente, contudo seu uso deve ter cuidados na manutenção e também estar associado a um bom plano de drenagem de águas pluviais, pois somente as gramas não seriam suficiente para absorver toda quantidade de águas das chuvas. 
Revista Nacional de

Gerenciamento de Cidades

Podemos dizer que ordenar o território envolve ações teóricas e práticas. Com isso temos por um lado os estudos, pareceres técnicos, relatórios e documentos que organizam uma certa região. É a parte teórica. Por outro lado, temos os interesses políticos, os interesses capitalistas, as necessidades da população, enfim, essa é a parte prática.

Buscou-se analisar como as políticas habitacionais do DF, associadas ao planejamento urbano tem perpetuado a segregação social e residencial entre seus habitantes e dialeticamente tem também promovido 0 desenvolvimento socioeconômico da cidade de São Sebastião, antes desprovida de ações governamentais.

O governo inaugurado em 2003 representa um marco na política urbana brasileira. Realmente é visível o aumento das construções de habitações em vários municípios brasileiros. Vemos no Distrito Federal especificamente, as obras de prédios destinados à moradia tanto pelas empresas privadas como obras associadas com as políticas habitacionais. A construção civil está tendo um crescimento elevado, principalmente devido às construções de habitações. O crescimento populacional e o processo de urbanização em si tem promovido a expansão desse setor.

Observa-se que a moradia tem tido papel de destaque nas políticas públicas, e que tem sido um dos problemas urbanos que mais receberam investimentos por parte dos governos nas esferas federal, estadual e municipal. Vale destacar que o fato de todas as pessoas necessitarem de moradia, faz de cada família um demandante em potencial no mercado de habitação, isso também justifica o crescimento do mercado imobiliário na atualidade.

Independentemente do nível de renda, todos precisam de moradia e o alto preço da habitação torna sua comercialização dependente de esquemas de financiamento de longo prazo. A durabilidade elevada desse bem faz com que políticas habitacionais antigas influenciem no atual estado do mercado. Logo, o atual estágio das políticas voltadas para a construção de moradias é fruto de políticas antigas que não atendiam ao crescimento populacional e a 


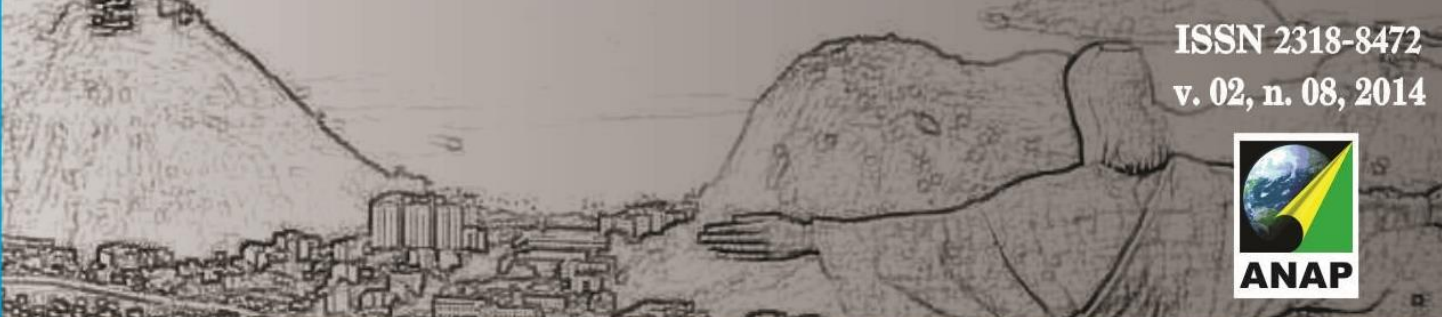

Revista Nacional de

Gerenciamento de Cidades

expansão da cidade como um todo. $E$ hoje o que tem expandido na construção civil é a oferta de bairros planejados que são construídos tendo por base a preocupação socioambiental e sustentável, quando adota práticas que privilegiam o espaço verde e a adoção de práticas que minimizem a destruição ambiental.

\section{REFERÊNCIAS}

BENKO, Georges. Economia, espaço e globalização: na aurora do século XXI. Tradução: Antonio de Pádua Danesi. 3 ed. São Paulo: Hucitec: Annablume, 2002. (p.19-47)

CASTELLS, Manuel. A Questão urbana. Tradução de Arlene Caetano. Rio de Janeiro: Paz e Terra, 1983. (p.35-49)

CASTELLS, Manuel. A sociedade em rede. Tradução: Roneide Venâncio Majer. São Paulo: Paz e Terra, 1999. (p.43-71)

CHESNAIS, François. A mundialização do capital. Tradução Silvana Finzi Foá. São Paulo: Xamã, 1996. (p.22-33)

CLARK, David. Introdução à Geografia Urbana (tradução Lucia Helena de Oliveira Gerardi. Silvana Maria Pintaudi). São Paulo: DIFEL, 1985. p. 103-117

Condomínios do bairro Jardins Mangueiral. Disponível em: http://www.bairrojardinsmangueiral.org.br/condominos-do-bairro-jm. Acesso em 25/05/2014.

CORRÊA, Roberto Lobato. O espaço urbano. São Paulo: Ática, 1989. p. 7-3

HARVEY, David. A produção capitalista do espaço. São Paulo: Annablume, 2005.p. 165180. (Coleção Geografia e Adjacências).

Instituto EcoAnama. Disponível em: http://institutoecoanama2.blogspot.com.br/. Acesso em 27/05/2014.

O Jardins Mangueiral. Disponível em: http://www.jardinsmangueiral.com.br/. Acesso em 27/05/2014.

Os benefícios da grama. Disponível em: http://jiquitaia.com/index.php/clientes/78-jiquitaia/70os-beneficios-da-grama.

Acesso em 27/05/2014

SANTOS, Milton. A Natureza do Espaço: Técnica e Tempo, Razão e Emoção. São Paulo: Editora da Universidade de São Paulo, 2002. (p.233-259)

SANTOS, Milton. Espaço e Método. 5 ed. São Paulo: Editora da Universidade de São Paulo, 2012. (p.35-67) 
Revista Nacional de

Gerenciamento de Cidades

SANTOS, Milton. Metamorfoses do Espaço Habitado: Fundamentos Teóricos e Metodológicos da Geografia. 6 ed. São Paulo: Editora da Universidade de São Paulo, 2012. (p.41-49)

SANTOS, Milton. Por uma outra globalização: do pensamento único à consciência universal. 10 ed. Rio de Janeiro: Record, 2003. (p.79-111). 